\title{
Teaching patient safety in the medical undergraduate program at the Universidade Federal de São Paulo
}

\author{
Ensino sobre segurança do paciente no curso de Medicina da \\ Universidade Federal de São Paulo
}

Elena Bohomol ${ }^{1}$, Isabel Cristina Kowal Olm Cunha ${ }^{1}$

\begin{abstract}
Objective: To analyze the Educational Project of the undergraduate medical course to verify what is taught regarding Patient Safety and to enable reflections on the educational practice. Methods: A descriptive study, using document research as strategy. The document of investigation was the Educational Project of the medical course, in 2006, at the Escola Paulista de Medicina of the Universidade Federal de São Paulo. The theoretical framework adopted was the MultiProfessional Patient Safety Curriculum Guide of the World Health Organization, which led to the preparation of a list with 153 tracking terms. Results: We identified 65 syllabus units in the Educational Project of the course, in which $40(61.5 \%)$ addressed topics related to Patient Safety. Themes on the topic "Infection prevention and control" were found in $19(47.5 \%)$ units and teaching of "Interaction with patients and caregivers" in 12 (32.5\%); however content related to "Learning from errors to prevent harm" were not found. None of the framework topics had their proposed themes entirely taught during the period of education of the future physicians. Conclusion: Patient safety is taught in a fragmented manner, which values clinical skills such as the diagnosis and treatment of diseases, post-treatment, surgical procedures, and follow-up. Since it is a recent movement, the teaching of patient safety confronts informative proposals based on traditional structures centered on subjects and on specific education, and it is still poorly valued.
\end{abstract}

Keywords: Patient safety; Education, medical, undergraduate; Hospitals, teaching; Education, medical; Curriculum; Schools, medical; Faculty

\section{RESUMO}

Objetivo: Analisar o Projeto Pedagógico do curso de graduação em Medicina para verificar o que se ensina sobre segurança do paciente e propiciar reflexões sobre a prática educacional. Métodos: Estudo descritivo, utilizando-se como estratégia a pesquisa documental. 0 documento de investigação foi o Projeto Pedagógico do curso de Medicina (ano base 2006), da Escola Paulista de Medicina da Universidade Federal de São Paulo. 0 referencial teórico adotado foi - Multi-Professional Patient Safety Curriculum Guide da Organização Mundial da Saúde, elaborando-se uma lista de 153 termos rastreadores. Resultados: Foram identificadas 65 unidades curriculares no Projeto Pedagógico do curso, dentre as quais $40(61,5 \%)$ lidavam com assuntos relacionados à segurança do paciente. Temas do tópico "Prevenção e controle da infecção" foram encontrados em 19 (47,5\%) unidades e 0 ensino sobre "Interação com paciente e cuidadores" em 12 (32,5\%), no entanto, conteúdos relacionados a "Aprendendo com os erros para evitar danos" não foram encontrados em nenhuma. Verificou-se que nenhum dos tópicos do referencial teve os temas propostos ensinados em sua totalidade durante o período de formação do futuro médico. Conclusão: 0 ensino sobre segurança do paciente é ministrado de forma fragmentada valorizando-se as habilidades clínicas como diagnóstico e tratamento da doença, pós-tratamento, procedimentos cirúrgicos e acompanhamento. Por se tratar de um movimento recente, o ensino sobre segurança do paciente se confronta com propostas formativas baseadas em estruturas tradicionais, centradas nas disciplinas e na formação específica, sendo ainda pouco valorizado.

Descritores: Segurança do paciente; Educação de graduação em Medicina; Hospitais de ensino; Educação médica; Currículo; Escolas médicas; Docentes

\section{INTRODUCTION}

A new discussion, which has been going on in the training process of healthcare professionals, is the

\footnotetext{
${ }^{1}$ Universidade Federal de São Paulo, São Paulo, SP, Brazil

Corresponding author: Elena Bohomol - Rua Napoleão de Barros, 754 - Vila Clementino - Zip code: 04024-002 - São Paulo, SP, Brazil - Phone: (55 11) $3021-2546$ - E-mail: ebohomol@uol.com.br Received on: Feb 18, 2014 - Accepted on: Oct 7, 2014

Conflict of interest: none

DOI: 10.1590/\$1679-45082015A03089
} 
introduction of content related to patient safety because of the magnitude and frequency of errors and adverse events that occur during care. Undergraduate students are expected to develop skills since the beginning of their academic life to maximize measures that prevent such situations. ${ }^{(1)}$

In this sense, educators need to be prepared to create new proposals to development the students' skills. ${ }^{(2)}$ Educators need to develop learning experiences to provide the students the opportunity to use scientific evidence, describe the components of patient-centered care, identify mistakes in their own practice, and determine which actions need to be taken for their correction. . $^{(2,3)}$

The World Health Organization developed a guide for multiprofessional teaching on patient safety focused on the education of students in healthcare programs, and to help professors to deal with this topic. ${ }^{(1)}$

In Brazil, the National Program for patient safety was launched with the objective of monitoring and preventing harmful incidents in patient's care at the healthcare system. It also establishes that teaching institutions must include content in undergraduate program, making this an urgent topic for discussion at schools. ${ }^{(4)}$

In this way, the challenge is made for educating undergraduates on the aspects involving patient safety, to fill in a knowledge gap; i.e. how to develop specific awareness and actions at the teaching institutions.

\section{OBJECTIVE}

To analyze the Educational Project of the medical undergraduate program, to verify what is taught about patient safety and provide reflections on this educational practice.

\section{METHODS}

A descriptive study approved by the Research Ethics Committee of the Universidade Federal de São Paulo (UNIFESP), protocol CAAE no. 01737112.1.0000.5505. Document research was used as a strategy and the investigated document was the Educational Project (EP) of the medical undergraduate program in the school year of 2006.

The Escola Paulista de Medicina - UNIFESP was the site of the investigation, since it is nationally and internationally known for the training of professionals and for being a pillar of quality in teaching and research.
The reference adopted was the Multi-Professional Patient Safety Curriculum Guide, with 11 integrated topics for the development of the different contents. ${ }^{(1)}$

A list is prepared of self-reported keywords on the guide sheet and another list of possible themes to be taught; their evaluation was performed by two judges, educators, and researchers on the theme, after agreeing to participate in the study by signing the Informed Consent Form.

We found 153 tracked terms, distributed into 11 topics used for the search in the EP, performed between October 2012 and April 2013. Once located, the term and its correspondence in the program content, written under the responsibility of a lecturer of the curricular unit, the topic was identified in order to know the convergence with the themes proposed by the guide. The topics served as categories for analysis.

\section{RESULTS}

We identified 65 curricular units in the EP of the medical undergraduate program, and $40(61.5 \%)$ of them dealt with subjects related to patient safety (Table 1$)$.

Table 1. Distribution of the curricular units involved in teaching on patient safety in the medical undergraduate program

\begin{tabular}{lc}
\hline Topic of the guide & CU \\
& $\begin{array}{c}\mathbf{n = 4 0} \\
\mathbf{n}(\%)\end{array}$ \\
\hline What is patient safety? & $1(2.5)$ \\
Why applying human factors is important for patient safety? & $1(2.5)$ \\
Understanding systems and the effect of complexity on patient? & $2(5)$ \\
Being an effective team player & $7(17.5)$ \\
Learning from errors to prevent harm & 0 \\
Understanding and managing clinical risk & $5(12.5)$ \\
Using quality improvement methods to improve care & $1(2.5)$ \\
Engaging with patients and carers & $13(32.5)$ \\
Infection prevention and control & $19(47.5)$ \\
Patient safety and invasive procedures & $6(15)$ \\
Improving medication safety & $9(22.5)$ \\
\hline CU: curricular units. &
\end{tabular}

Chart 1 presents all the terms tracked used besides presenting those that were identified in the curricular units. 
Chart 1. Terms tracked regarding teaching on patient safety in the medical undergraduate program, as per the topics of the World Health Organization Manual

\begin{tabular}{|c|c|}
\hline Topic & Educational Project of the Medical Undergraduate Program \\
\hline \multirow[t]{14}{*}{ What is patient safety? } & General view of what safety is - concepts and definitions \\
\hline & Systems theory \\
\hline & History of patient safety \\
\hline & Adverse event \\
\hline & Health errors* \\
\hline & Failures in systems \\
\hline & Difference between failures, violation, and error \\
\hline & Human and economic costs associated with adverse events \\
\hline & Causes of errors \\
\hline & Swiss cheese model \\
\hline & Culture of guilt \\
\hline & Culture of safety \\
\hline & Models of safety \\
\hline & Patient-centered care \\
\hline \multirow{9}{*}{$\begin{array}{l}\text { Why applying human factors is important for } \\
\text { patient safety? }\end{array}$} & Concepts of human fallibility and perfection \\
\hline & Systems \\
\hline & Ergonomics* \\
\hline & Human factors \\
\hline & Work environment and its "noises"* \\
\hline & Fatigue and stress in professional performance \\
\hline & Man-machine relations and safety in the use of equipment \\
\hline & Communication strategies in the work environment \\
\hline & Redesigning processes \\
\hline \multirow{10}{*}{$\begin{array}{l}\text { Understanding systems and the effect of } \\
\text { complexity on patient? }\end{array}$} & Concepts and definition of systems and complex systems \\
\hline & Healthcare system* \\
\hline & Organizational structure ${ }^{*}$ \\
\hline & Work processes \\
\hline & Failures in the system and mechanisms for investigation of factors \\
\hline & Defenses and barriers in the systems \\
\hline & Comprehension and management of clinical risk \\
\hline & Authority with responsibility \\
\hline & Interdisciplinarity \\
\hline & Highly trustworthy organizations \\
\hline \multirow[t]{11}{*}{ Being an effective team player } & What is a team?* \\
\hline & The different types of teams found in healthcare* \\
\hline & Values, roles, and responsibilities* \\
\hline & Styles of learning \\
\hline & Hearing abilities \\
\hline & Team coordination \\
\hline & Effective leadership* \\
\hline & Characteristics of successful teams \\
\hline & Effective communication and communication tools* \\
\hline & Conflict resolution \\
\hline & Team work performance evaluation \\
\hline \multirow[t]{9}{*}{ Learning from errors to prevent harm } & Errors \\
\hline & Main types of errors \\
\hline & Violations, errors, near-misses \\
\hline & Situations that increase the risks of errors \\
\hline & Individual factors that predispose to error \\
\hline & How to learn from errors \\
\hline & Incident report \\
\hline & Adverse event analysis \\
\hline & Strategies to reduce errors \\
\hline
\end{tabular}

* Tracking terms used that were also identified in the curricular units.

PDSA: Plan, Do, Study, Act; PDCA: Plan, Do, Check, Act. 
.... Continuation

Chart 1. Terms tracked regarding teaching on patient safety in the medical undergraduate program, as per the topics of the World Health Organization Manual

\begin{tabular}{|c|c|}
\hline Topic & Educational Project of the Medical Undergraduate Program \\
\hline \multirow[t]{15}{*}{ Understanding and managing clinical risk } & Risk management - definitions; \\
\hline & How to understand and manage clinical risks* \\
\hline & Notification of near-misses \\
\hline & Report of errors \\
\hline & Clinical monitoring* \\
\hline & Training programs to evaluate clinical risks \\
\hline & Notification* and monitoring of incidents \\
\hline & Types of incidents \\
\hline & Sentinel events \\
\hline & Communication of risks and dangers at the work place \\
\hline & Organization and work environment \\
\hline & Credetialling, licensing, and accreditation \\
\hline & Professional and individual responsibilities in risk management \\
\hline & Fatigue and stress \\
\hline & Communication and poor communication \\
\hline \multirow[t]{15}{*}{ Using quality improvement methods to improve care } & Theory of knowledge \\
\hline & Basic concepts of change \\
\hline & Deming's concepts \\
\hline & Management system with focus on process improvement \\
\hline & Continuous improvement \\
\hline & PDSA/PDCA Cycle \\
\hline & Quality tools: flow chart, Ishikawa chart, Pareto diagram, and histogram \\
\hline & Indicators* \\
\hline & Variation, methods for quality improvement \\
\hline & Result measures \\
\hline & Process measures \\
\hline & Compensation measures \\
\hline & Clinical practice improvement \\
\hline & Root cause analysis \\
\hline & Analysis of modes and effects of failure \\
\hline \multirow[t]{16}{*}{ Engaging with patients and carers } & The voice of the consumer \\
\hline & Patient rights* \\
\hline & Protection legislation for consumer protection and user rights of the healthcare system* \\
\hline & Complaints \\
\hline & Fear \\
\hline & Education* \\
\hline & Principles of good communication* \\
\hline & Communication tools: SPIKE, SEGUE, SPEAK UP \\
\hline & Informed consent* \\
\hline & Respect for the differences of each patient, as to religious, cultural and personal beliefs, and as to individual needs* \\
\hline & Patient privacy and autonomy \\
\hline & Responsibility and family* \\
\hline & Ways of involving the patients and professionals in health-related decisions* \\
\hline & Asking for forgiveness \\
\hline & Open revelation process \\
\hline & Legal implications of the error \\
\hline \multirow[t]{5}{*}{ Infection prevention and control } & Healthcare-related infection* \\
\hline & Precautions to prevent and control infections* \\
\hline & Infections in the community* \\
\hline & Transmission and cross transmission* \\
\hline & Alerts of epidemics and pandemics \\
\hline
\end{tabular}

* Tracking terms used that were also identified in the curricular units.

PDSA: Plan, Do, Study, Act; PDCA: Plan, Do, Check, Act. 
.... Continuation

Chart 1. Terms tracked regarding teaching on patient safety in the medical undergraduate program, as per the topics of the World Health Organization Manual

\section{Topic}

Educational Project of the Medical Undergraduate Program

Infection prevention and control

Types of transmission*

Risks of infection*

Asepsis techniques*

Aseptic*

Standard precautions

Economic cost associated with infection

Individual protection equipment

Instrument and equipment sterilization and disinfection methods

Multiresistant organisms*

Antimicrobial resistance*

Recommendations on the single use of devices

Hand washing*

Guidelines: for use of gloves, isolation, of the Centers for Disease Control and Prevention

Immunizations, vaccines*

World Health Organization program: Clean Care is Safe Care; campaigns for hand hygiene; control of antimicrobial use

Patient safety and invasive procedures

Adverse events associated with surgical procedures and with other invasive procedures

Complications at the surgical site*

Infection at surgical site*

Infection control in surgical care*

Preexisting factors for the occurrence of errors

Communication failures among teams

Verification processes

Team work

Surgical complications

Surgical gowning

Laterality

Practices that reduce risks, such as time-out, briefing, debriefings, assertiveness, and information transmission systems

Patient management in the operating room*

Improving medication safety

Medication system and prescription, distribution, and administration process*

Drugs*

Control of antimicrobial use

Medication regulation

User access to the medications

Notification system for adverse events

Side effect

Adverse reaction to the medication*

Potential and real drug-drug and drug-food interaction

Medication errors and their types

Consequences for the Patient*

Sources of error and prevention

Patient monitoring and evaluation of clinical parameters*

Prescription*

Administration*

The five "correct things" in the medication system

Safe communication process among the teams to minimize errors

Use of technology in order to minimize errors

Physical, cognitive, emotional, and social factors that predispose towards patient vulnerability when using medications

Drug reconciliation

High-vigilance medications (potentially dangerous or of high risk)

* Tracking terms used that were also identified in the curricular units.

PDSA: Plan, Do, Study, Act; PDCA: Plan, Do, Check, Act. 


\section{DISCUSSION}

Although the school represents a mark of excellence in medical practice training, there are gaps in teaching about patient safety. Therefore, there is a need to rethink the content in order to structure a syllabus that addresses what students should know, presenting new perspectives in face of current the transformations in education. For this reason, a few reflections are made by the authors as a form of instigating their discussion in the EP of the course studied.

The study allowed the verification of the fact that several themes related to patient safety are ministered throughout the undergraduate course in different curricular units. However, teaching is fragmented throughout the course, making it clear that content that is valued is that which develops clinical abilities, such as diagnosis and treatment, post-treatment, and follow-up.

The school also has a training proposal based on a traditional structure, centered on subjects and specific training. Some studies recommended that instruction on patient safety should be contemplated on a transversal axis, allowing an interdisciplinary and transdisciplinary conduction. $^{(1,5)}$ Interdisciplinary practice implies interdependence, interaction, and communication among the fields of knowledge, or subjects, enabling integration of knowledge in significant areas, seeking unity of knowledge.(6) Transdisciplinarity stimulates a new understanding of reality, articulating elements that pass among, beyond, and through the subjects, in a search for comprehension of the complexity. This would be an empathetic attitude of openness to the other, allowing the sum of different understandings for the dissemination of knowledge and the development of skills in the undergraduate students. ${ }^{(7)}$

Many universities in the world (rarer in Brazil) have carried out studies on specific themes about education in patient safety, notably reviewing the use of traditional teaching methodologies and incorporating strategies to improve learning. The experience of the University of Saskatchewan, in Canada, points towards success in the development of interprofessional skills for students from different undergraduate courses in the area of health, using methods of quality improvement to perfect patient-centered care. ${ }^{(5)}$

It was noted that little is taught about human fallibility when themes such as failure, violation, pursuit of perfection, or culture of guilt are not covered. Fallibility, in medical practice, was already contextualized in the field of Philosophy and Ethics, in 1976. The proposed theory reports that fallibility in this area is the least understood, that the damaging error is amply denied because it is intensely feared: medical error not only happens, but it is inevitable yet today. ${ }^{(8)}$

In this respect, the Medical School of the University of Missouri in Columbia, United States, proposed changes in their curriculum upon verifying that all the members of a healthcare team, including the secondyear students, were able to recognize unsafe situations, systematically notify errors, suggest improvements to the system, and understand human fallibility, bringing to light the revealing of the errors to the patients. They introduced various themes about patient safety (error notification; safety tools, such as root cause analysis), and reviewed their teaching strategies, using readings, integrative forums, discussion panels, and drama. ${ }^{(3)}$

Concepts developed in the field of the exact sciences, such as Human Factors Engineering (HFE), man-machine relations, or redesigning of processes are still not taught. They take into consideration not only the interaction between the machine and the human body, but also the interaction with the mind in the work environment. In the field of HFE, one basic principle is that the most efficient sequence of movements, which does not necessarily represent the quickest, is generally the safest, because the performance of fewer movements reduces the risk of incident. ${ }^{(9)}$ These principles also apply to healthcare.

Students learn what a team is, but there is a lack of concepts as to what successful teams are, since in Medicine, emergency situations are lived with a high level of stress and that require good results. The term comes from safety of aircrafts in flight and the prevention of aeronautic accidents, called Crew Resource Management. Its purpose is to analyze and interact, with respect to human relations, in groups that are the primary determinants of the performance of teams responsible for conducting an aircraft. Its practical application pursues the skills that allow the professionals to manage the entire work process in a satisfactory way, especially the decision-making process, so that the resulting decisions are appropriate and opportune in terms of safety and precision. ${ }^{(10)}$ Such aspects may be developed in teaching healthcare as well.

There is yet the concern as to how the school trains the future physician as part of a multiprofessional team, preventing so-called disruptive behavior. This behavior refers to personal conduct, whether verbal or physical, that negatively affects or can potentially compromise care given the patient. ${ }^{(11)}$

Some aspects, such as privacy and autonomy of the patient, are still a challenge in student training, since patients enter a teaching hospital, and as such, are subject to the act of the medical students. The students 
want and need to develop their skills. However, not only clinical aspects must be taught, but also those that refer to rights of the users, such as respect for privacy and comfort; individuality; ethical, cultural, and religious values; confidentiality of every and any personal information; safety of the procedure; and psychic and emotional well-being. ${ }^{(12)}$

To discuss the errors of the undergraduates is also a form of learning, since these errors may happen during training. However, there should be no fear or dread of damaging an evaluation if they are revealed. Therefore, the attitude of the lecturer is important, since he/she should create an encouraging environment for the communication of errors and perform a systemic analysis of its causes, demonstrating positive answers for the students when they report the errors, in a commitment to an improvement process that can be incorporated. ${ }^{(13)}$

Although the study allows other reflections, it has limitations. One hundred and fifty-three tracking terms were used to capture themes and content, but it is possible that some curricular units were not included because of synonyms that were not considered. Document analysis was the strategy chosen, based on the content written in the formal syllabus. The true and the hidden syllabuses, also used by lecturers, were not studied.

\section{CONCLUSION}

The study allowed the identification of the themes related to the teaching of patient safety that are included in the Educational Projects and converge as to the guidelines of the World Health Organization. Nevertheless, there are many gaps in the educational proposal of the course, demonstrating that teaching is fragmented, and there is no interdisciplinary or transdisciplinary guidance.

Studies about the teaching of patient safety in Medical School courses are still scarce, suggesting other investigations to fill the knowledge gap on how to train physicians who will be able to minimize adverse events in health.

\section{REFERENCES}

1. World Health Organization (WHO). Patient safety curriculum guide: multiprofessional edition [lnternet]. Geneva: WHO; 2011 [cited 2013 Jul 31]. Available from: http://whqlibdoc.who.int/publications/2011/9789241501958_eng.pdf

2. Kiersma ME, Plake KS, Darbishire PL. Patient safety instruction in US health professions education. Am J Pharm Educ. 2011;75(8):162. Review.

3. Madigosky WS, Headrick LA, Nelson K, Cox KR, Anderson T. Changing and sustaining medical students' knowledge, skills, and attitudes about patient safety and medical fallibility. Acad Med. 2006;81(1):94-101.

4. Brasil. Ministério da Saúde. Portaria n. 529, de 1 de abril de 2013. Institui o programa nacional de Segurança do Paciente (PNSP) [Internet]. Diário Oficial da República Federativa do Brasil, Brasília (DF); 2013 [citado 2013 Jul 31]. Disponível em: http://bvsms.saude.gov.br/bvs/saudelegis/gm/2013/ prt052901_04_2013.html

5. Dobson RT, Stevenson K, Busch A, Scott DJ, Henry C, Wall PA. A quality improvement activity to promote interprofessional collaboration among health professions students. Am J Pharm Educ. 2009;73(4):64.

6. A construção do projeto político-pedagógico da escola. Moodle UFBA Módulo experimental [Internet]. Salvador: Universidade Federal da Bahia; 2007 [citado 2013 Jul 31]. Disponível em: http://www.moodle.ufba.br/mod/ book/view.php?id =14550\&chapterid $=10905$

7. Rocha Filho JB, Basso NR, Borges RM. Transdisciplinaridade: a natureza íntima da educação científica. 2a ed. Porto Alegre: EDIPUCRS; 2009.

8. Gorovitz S, Maclntyre A. Toward a theory of medical fallibility. Hastings Cent Rep. 1975;5(6):13-23.

9. Karsh BT, Holden RJ, Alper SJ, Or CK. A human factors engineering paradigm for patient safety: designing to support the performance of the healthcare professional. Qual Saf Health Care. 2006;15 Suppl 1:i59-65. Review.

10. Lupoli Junior JG, Angelo CF, Tanabe M. 0 comportamento de equipe em processos decisórios gerenciais: um experimento com grupos de trabalho. Rev Adm Eletrônica. 2008;1 (2):art.3.

11. Halverson AL, Neumayer L, Dagi TF. Leadership skills in the OR: Part II: Recognizing disruptive behavior. Bull Am Coll Surg. 2012;97(6):17-23.

12. Brasil. Ministério da Saúde. Carta dos direitos dos usuários da saúde [Internet]. 3a ed. Brasília (DF): Ministério da Saúde, 2011 [citado 2013 Jul 31]. Disponível em: http://www.conselho.saude.gov.br/biblioteca/livros/AF Carta_Usuarios_Saude_site.pdf

13. Koohestan HR, Baghcheghi N. Barriers to the reporting of medication administration errors among nursing students. Aust J Adv Nurs. 2009; 27(1):66-74. 